of the popular tools to analyse genetic diversity. It helps determine the relative contribution of different component traits in the total variability. Besides, it is also equally important in determining the degree of variability between populations. This is essential while selecting parents with wide diversity in order to have fruitful recombinations. In the present study, 20 plus trees/ genotypes of $S$. alba were resolved into five clusters following non-Euclidean hierarchical cluster analysis (Table 2 and Figure 1). This type of clustering pattern revealed no relation between geographical and genetic diversity. The genetic diversity may be attributed to different factors such as differential adoption methods, selection criteria, selection pressure and environment factors ${ }^{18}$, which indicates that genetic drift resulted into greater diversity than that of geographic diversity ${ }^{19}$. Earlier studies in Jatropa curcas $^{12}$, Pongamia pinnata ${ }^{13}$ and Madhuca latifolia ${ }^{16}$ are in line with the present findings, where no relation was observed between genetic diversity and geographical distribution. This can be attributed to the changes that these trees may have undergone during the process of selection. Plus trees in clusters II and I could be used for hybridization within groups as they were diverse and had maximum intra-cluster distance. Similarly, wider genetic diversity was observed between clusters V and IV, as they had maximum inter-cluster distance, followed by clusters IV and I. Thus, these groups can be utilized for hybridization, which will definitely yield fruitful results in the form of variable segregants having desired traits. This will be helpful in the improvement of the tree species in question.

1. Argus, G. W., Infrageneric classification of Salix L. (Salicaceae) in the New World. Syst. Bot. Monogr., 1997, 52.

2. Skvortsov, A. K., Willows of Russia and Adjacent Countries: Taxonomical and Geographical Revision (transl. from: Skvortsov, A.K., Willows of the USSR: Taxonomic and Geographic Revision, Nauka, Moscow), 1968, Joensuu University, Joensuu, Finland, 1999.

3. Kuzovkina, Y. A. and Quigley, M. F., Willows beyond wetlands: uses of Salix L. species for environmental projects. Water Air Soil Pollut., 2005, 162, 183-204.

4. Trybush, S., Jahodova, S., Macalpine, W. and Karp, A., A genetic study of Salix germplasm resource reveals new insights into relationships among subgenera, sections and species. Bioenergy Res. 2008, 1(1), 67-79.

5. Dar, U. and Kachroo, P., Alpine Flora of Kashmir Himalaya, Scientific Publishers, Jodhpur, 1983, p. 169.

6. Luna, R. K., Plantation Trees, Publishing Corporation, International Book Distributors, Dehradun, 1995, pp. 640-645.

7. CSIR, Plants for Reclamation of Wastelands, CSIR, New Delhi, 1990.

8. Weber, E., Genetic Der Salix alba L. An. Za Sumarstvo, 1974, 6, $5-25$.

9. Chaturvedi, O. P. and Pandey, N., Genetic divergence in Bombax ceiba L. germplasms. Silvae Genet., 2001, 50, 99-102.

10. Ayad, W. G., Hodgkin, A. J. and Rao, U. R., Molecular Genetic Techniques for Plant Genetic Resources. International Plant Genetic Resources Institute Report, Maccarese, Rome, 1995.
11. Gradual, L., Kjaer, E. D., Suangtho, P. and Kaossard, A., Conservation of genetic resources of teak (Tectona grandis) in Thailand. Technical Note No. 52, Danida Forest Seed Center, Denmark, 1999.

12. Rao, G. R., Korwar, G. R., Shanker, A. K. and Ramakrishna, Y. S., Genetic associations, variability and diversity in seed characters, growth, reproductive phenology and yield in Jatropha curcas (L.) accessions. Trees, 2008, 22, 697-709.

13. Rao, G. R., Shanker, A. K., Srinivas, I., Korwar, G. R. and Venkateswarlu, B., Diversity and variability in seed characters and growth of Pongamia pinnata (L.) Pierre accessions. Trees, 2011, 25, 725-734.

14. Divakara, B. N. and Das, R., Variability and divergence in Pongamia pinnata for further use in tree improvement. J. For. Res., 2011, 22(2), 193-200.

15. Singh, N. B. and Chaudhary, V. K., Multivariate analysis of genetic divergence in wild apricot (Prunus armeniaca Linn.). Indian J. For., 1992, 15, 211-216.

16. Divakara, B. N., Relationship of seed traits on initial progeny growth performance and divergence studies in Madhuca latifolia Macb. for further use in tree improvement. J. Trop. For. Environ., 2014, 4(2), 11-23.

17. Rao, C. R., Advanced Methods in Biometrical Research, John Wiley, New York, 1952.

18. Vivekananda, P. and Subramaninan, S., Genetic divergence in rainfed rice. Oryza, 1993, 39, 60-62.

19. Singh, A. K., Singh, S. B. and Singh, S. M., Genetic divergence in scented and fine genotypes of rice (Oryza sativa L.). Ann. Agric. Res., 1996, 17, 163-166.

Received 24 December 2016; revised accepted 8 November 2017

\section{Estimating net primary productivity of croplands in Indo-Gangetic Plains using GOME-2 sun-induced fluorescence and MODIS NDVI}

\author{
N. R. Patel ${ }^{1}$, Hitendra Padalia ${ }^{1, *}$, R. Devadas ${ }^{2}$, \\ A. Huete ${ }^{2}$, A. Senthil Kumar ${ }^{1}$ and \\ Y. V. N. Krishna Murthy ${ }^{3}$ \\ ${ }^{1}$ Indian Institute of Remote Sensing, Dehradun 248 001, India \\ ${ }^{2}$ University of Technology Sydney, Sydney, Australia \\ ${ }^{3}$ National Remote Sensing Centre, Hyderabad 500 072, India
}

Recently evolved satellite-based sun-induced fluorescence (SIF) spectroscopy is considered as a direct measure of photosynthetic activity of vegetation. We have used monthly averages of satellite-based SIF retrievals for three agricultural year cycles, i.e. May to April for each of the three years, viz. 2007-08,

*For correspondence. (e-mail: hitendra@iirs.gov.in) 
2008-09 and 2009-10 to assess comparative performance of SIF and normalized difference vegetation index (NDVI) for predicting net primary productivity (NPP) over the Indo-Gangetic Plains, India. Results show that SIF values for C4 crop-dominated districts were higher than $\mathrm{C} 3$ crop-dominated districts during summer and low during winter for all three years. SIF explained more or less above $70 \%$ of variance in NPP. The variance explained by integrated NDVI ranged from $60 \%$ to $67 \%$. Thus the present study has shown the potential of SIF data for improved modelling of agricultural productivity at a regional scale.

Keywords: Crop lands, net primary productivity, photosynthetic activity, sun-induced fluorescence.

AGRICULTURAL systems have received less attention by carbon science groups across the world, besides that they cover around 15 million sq. $\mathrm{km}$ of the terrestrial surface and approximately more than half of the land area in India. Scientific evidence suggests that intensively managed agricultural systems act as a $\mathrm{CO}_{2}$ sink. Reliable and consistent spatial databases on productivity of agricultural systems on a national scale are crucial for securing food security.

Satellite-based crop monitoring is a key to food security. Newly developed satellite-based spectroscopy is geared to improve crop monitoring, as it allows monitoring of photosynthesis through detection of key physiological traits, viz. xanthophyll cycle pigments and chlorophyll fluorescence. Traditionally, effectiveness of remote sensing-based vegetation indices as direct proxies or as input of light use efficiency models for estimating agricultural productivity remains highly uncertain, particularly in managed croplands. These process-based crop models generally over estimate and ecosystem models underestimate the potential productivity of crops under real field conditions.

Augmenting reflectance-based vegetation indices, satellite-based estimates of sun-induced fluorescence (SIF) have now become available for large-area estimate of crop productivity. Satellite-based estimation of SIF is an early and direct measure of photosynthetic activity of the vegetation and SIF is an indicator of light use efficiency, vegetation stress and global primary productivity (GPP) $)^{1}$.

A part of the energy absorbed by chlorophyll is expelled from the light reactions of photosynthesis and dissipated as fluorescence, i.e. re-emission of light at a longer wavelength than for excitation (Figure 1) ${ }^{2}$. Satellite-based observation of SIF was accomplished mainly through the utilization of weak signal contribution in the Fraunhofer line wavelengths ${ }^{3}$. Near infrared (NIR) solar Fraunhofer lines filled-in by vegetation fluorescence were used to estimate global terrestrial fluorescence with high spectral resolution Greenhouse gases Observing SATellite $(\text { GOSAT })^{4-6}$.
Joiner et $a l .^{7}$ retrieved the far-red chlorophyll fluorescence using satellite-based hyperspectral measurements close to $\mathrm{O}_{2}$ A band. This retrieval process exploited the different spectral structures produced by the far-red chlorophyll fluorescence feature, atmospheric absorption and surface reflectance. This algorithm was purported to be advantageous as nearby nonfluorescing target was not required for fluorescence measurements. This study used data from global ozone monitoring instrument-2 (GOME2) on-board MetOp-A platform. A similar approach using GOME-2 SIF data demonstrated that SIF retrievals could provide a direct estimate of the GPP of cropland and grassland ecosystems ${ }^{8}$.

We examined comparative performance of SIF and the most commonly used vegetation index, i.e. NDVI for estimating net primary productivity (NPP) of managed agricultural lands in the Indo-Gangetic Plains (IGP). We have utilized monthly averages of GOME-2 SIF retrievals over India at $0.5^{\circ}$ resolution for three agricultural year cycles, i.e. May to April for each of the three years, viz. 2007-08, 2008-09 and 2009-10.

The study area is the IGP covering six states, viz. Punjab, Haryana, Uttarakhand, Uttar Pradesh, Bihar and West Bengal. The IGP occupies nearly 15\% (0.7 million sq. $\mathrm{km}$ ) of the total land area of the country. The region is known for large stretches of fertile alluvium soil favourable for agriculture and produces about $50 \%$ of the total food grains in the country ${ }^{9}$. The study area is an intensively managed agroecosystems with major cropping systems like rice-wheat, sugarcane-wheat, maize-wheat, cotton-wheat, rice-potato, rice-mustard-jute and ricevegetable-jute.

We prepared cropland NPP inventory at the district level based on acreage and yield data of major crops for the years 2007-08, 2008-09 and 2009-10, and cropspecific conversion factors. Biomass partitioning factor (harvest index), moisture content and root: shoot ratio databases for major crops were collected from the literature. District-wise cropland NPP of the IGP was used for establishing relationships with SIF and NDVI. Harvestable

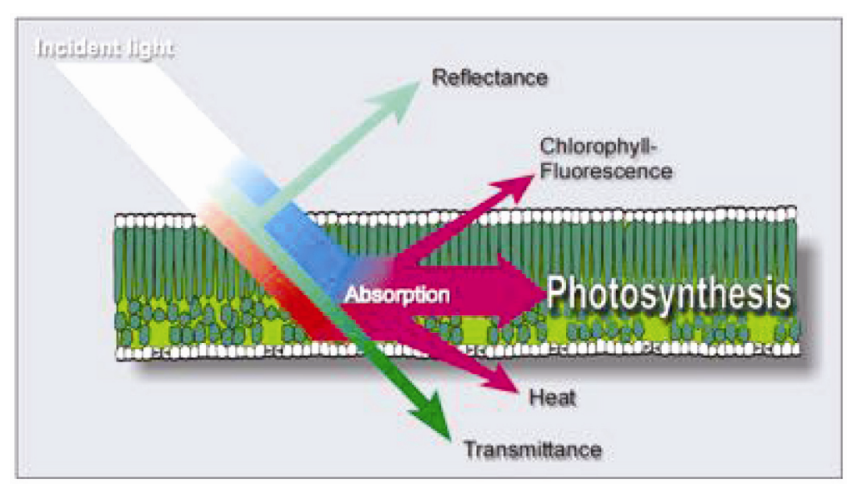

Figure 1. Distribution of solar energy incident on a green leafillustrated with the cross-section of a leaf (source: ref. 1). 
products at the district level were converted to NPP using crop-related parameters ${ }^{10}$

$$
\begin{aligned}
\mathrm{NPP} & \left(\mathrm{gCm}^{-2}\right) \\
& =\sum_{i=I}^{N} \frac{Y_{i} \times M Y_{i} \times\left(1-M C_{i}\right) \times 0.45 \mathrm{gC} / \mathrm{g}}{H_{i}} / \sum_{i=I}^{N} A_{i},
\end{aligned}
$$

where $\mathrm{gC} / \mathrm{g}$ is gram carbon/gram, $Y_{\mathrm{i}}$ the reported production for crop $i, M Y_{i}$ the mass per unit of harvestable product, $H_{i}$ the harvest index (seed : biomass ratio) for crop $i$, $M C_{i}$ the moisture content in seeds and $A_{i}$ is the harvest area of crop $i$. The numerator and denominator are summed over $N=16$ crops.

The GOME-2 version $26740 \mathrm{~nm}$ SIF data for the period from 2007 to 2014 were downloaded from Aura
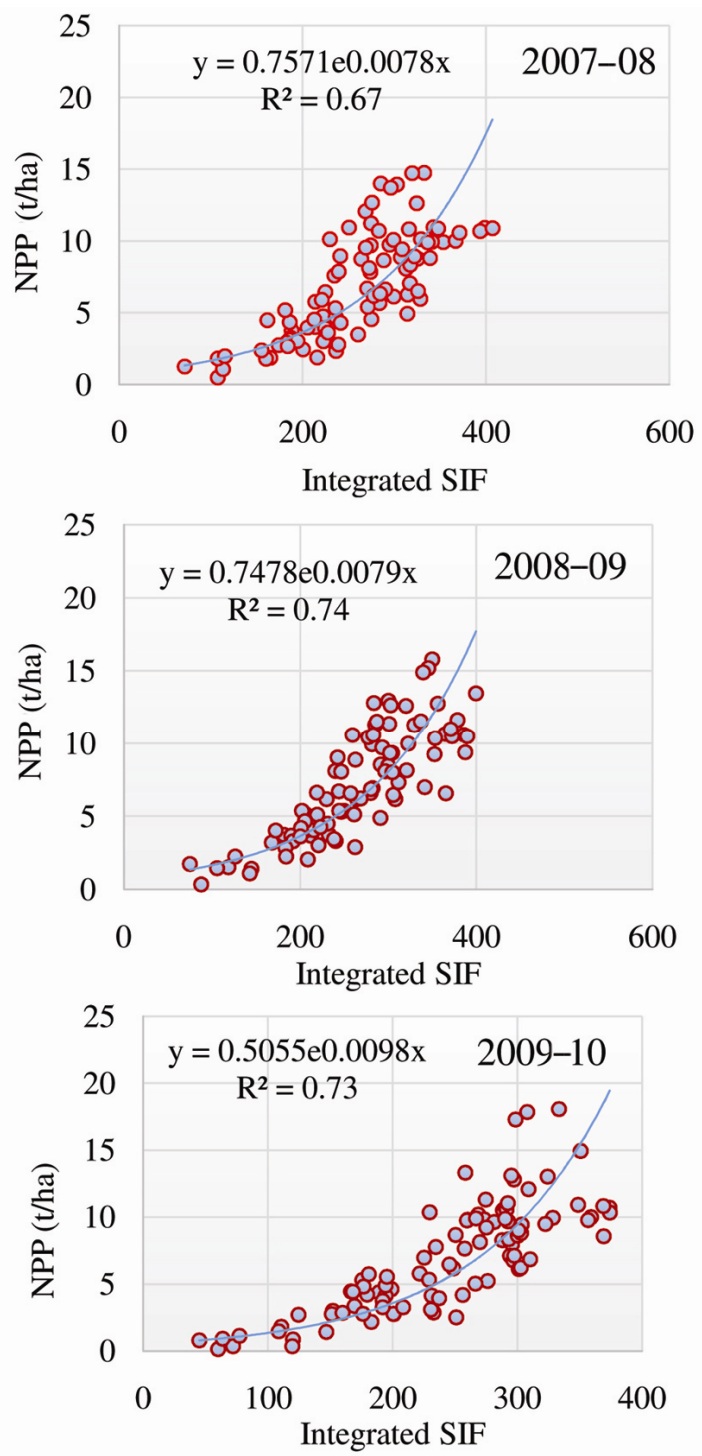

Figure 2. Relationship of cropland net primary productivity with integrated sun-induced fluorescence (iSIF) in IGP.
Validation Data Centre, NASA, USA ${ }^{6}$. The monthly datasets available since 15 July 2013 have a spatial resolution of approximately $40 \mathrm{~km} \times 80 \mathrm{~km}$ at nadir and $40 \mathrm{~km} \times$ $40 \mathrm{~km}$. GOME-2 SIF retrieval primarily corresponds to emission at $740 \mathrm{~nm}$ wavelength. Monthly composites of moderate resolution imaging spectroradiometer (MODIS)based NDVI (NIR-Red/NIR + Red) at $5 \mathrm{~km}$ spatial resolution, quality filtered for clouds, aerosols and extreme sun-sensor view geometries, were obtained from the VIP (Vegetation Index/Phenology) laboratory, University of Arizona.

We computed integral NDVI (iNDVI) covering the entire year in order to assess the annual NDVI using the following formula ${ }^{10}$

$$
\begin{aligned}
\mathrm{iNDVI} & =P / 2\left(\mathrm{NDVI} t_{1},\right. \\
& \left.+2 * \text { NDVI } t_{2},+2 * \text { NDVI } t_{3}+\cdots+2 * \text { NDVI } t_{n}\right),
\end{aligned}
$$

where $P$ is the number of months (i.e. 12) and $t_{1}, t_{2}$, $t_{3} \ldots, t_{n}$ are the months from May to April in each year.
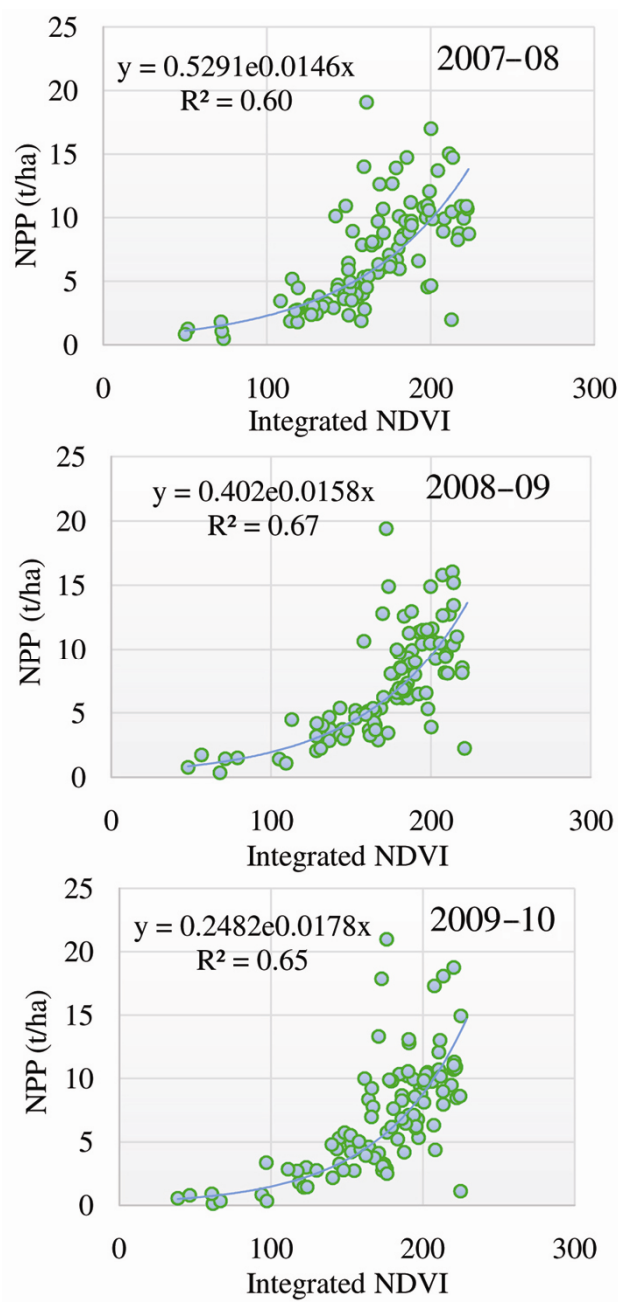

Figure 3. Relationship of cropland net primary productivity with integrated NDVI in IGP. 


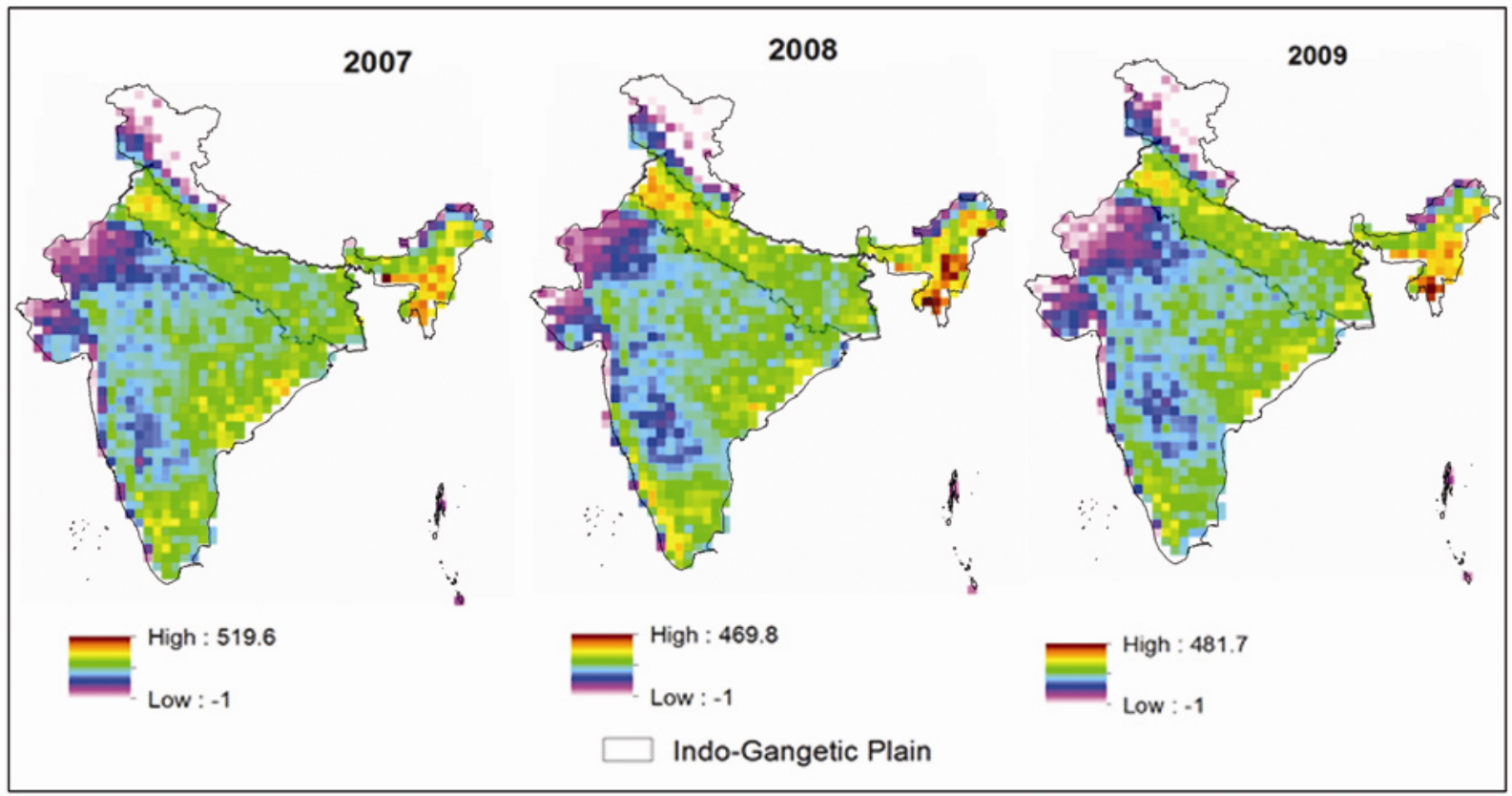

Figure 4. Spatio-temporal variability in SIF over the IGP for crop cycle years 2007, 2008 and 2009.
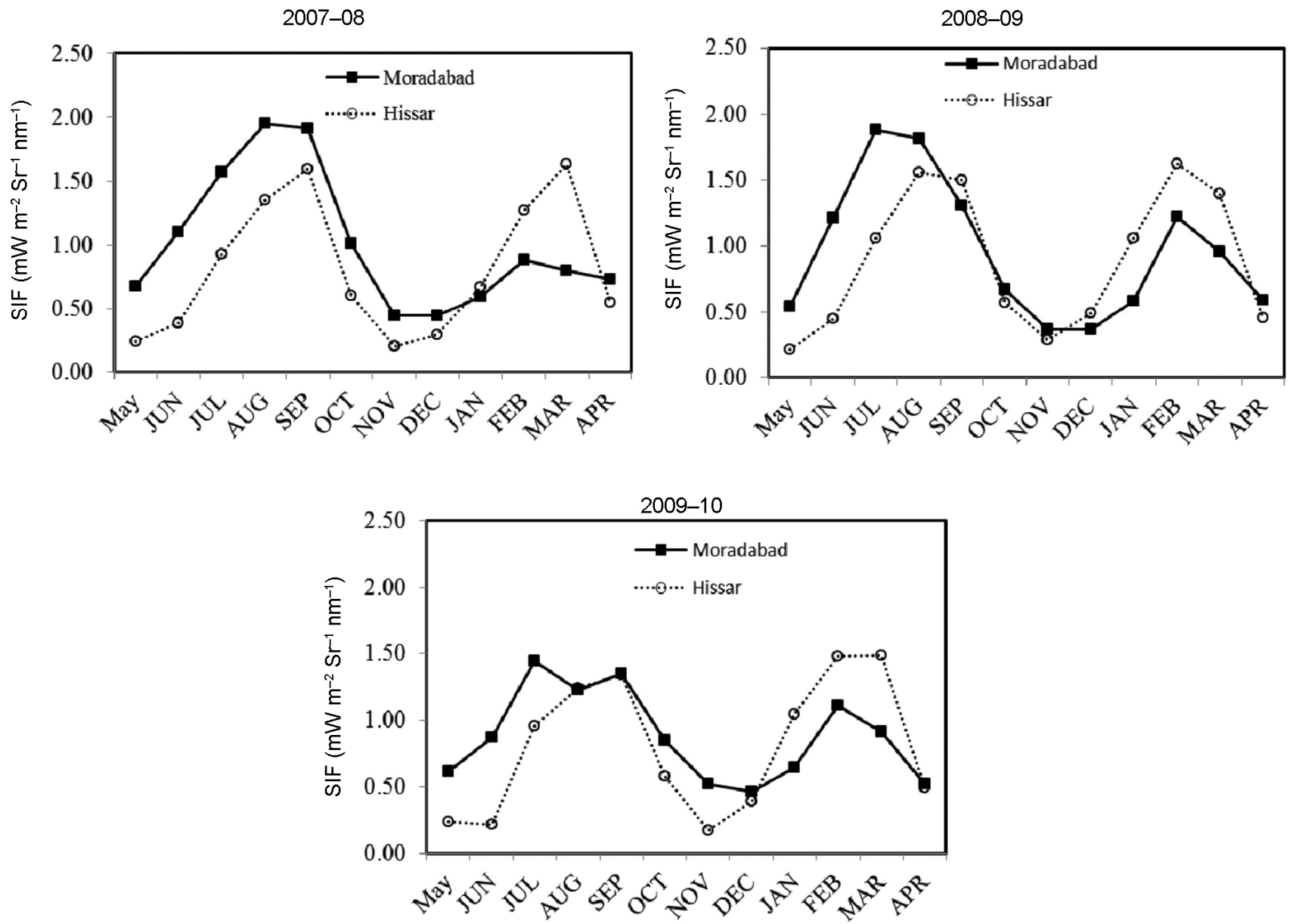

Figure 5. Temporal SIF trends over $\mathrm{C} 3$ and $\mathrm{C} 4$ crop-dominated districts of the IGP. 
Similar to iNDVI, iSIF (integrated SIF) was also calculated taking into account of monthly time series of SIF in a year to derive the annual iSIF.

About 115 districts having dominantly agricultural lands and covering a major portion of individual SIF grids were used for regression analysis. An exponential function better explained the NPP-SIF relationship for all the three crop cycles as indicated compared to that of a linear fitting. The temporal pattern of SIF was studied over C3 (wheat-rice) and C4 (sugarcane) dominant crop area for Hisar district, Haryana and Moradabad district, Uttar Pradesh.

The findings revealed that cropland NPP (t/ha) had strong links with SIF in comparison to NDVI (Figures 24). However, both iSIF and iNDVI over crop year showed exponential form of relation with NPP. Regardless of years and descriptive variables, linear fit offered significant but relatively low coefficient of determination $\left(R^{2}\right)$. The amount of variance in NPP explained by SIF was approximately above $70 \%$. The variance explained by iNDVI ranged from $60 \%$ to $67 \%$. Higher SIF value was recorded during the 2007-08 crop season, which coincided with higher rainfall recorded in the area for the period. Lower SIF peak was observed in the 2008-09 crop season during which period lower rainfall of the 2008-09 window was recorded (Figure 3). Detailed analysis is required to understand these inter-annual variations in prediction capability. Various climatic, land cover and management factors could play a crucial role in these assessments.

Temporal plot of SIF over Moradabad and Hissar districts showed distinct pattern owing to predominance of C3 or C4-based crops in these districts (Figure 5). In Moradabad district, the magnitude of SIF remained high and persisted for a longer duration due to input-intensive sugarcane-based cropping system. Sugarcane being a C4 and long-duration crop, has high photosynthesis rates and NPP. The average sugarcane yield (NPP) obtained in Moradabad for 2007-08, 2008-09 and 2009-10 was 56.4 (26.5), 54.3 (23.1) and 56.2 (24.5) tonnes/ha respectively. On the other hand, Hissar district is dominantly occupied C3 crops comprising cotton-wheat, rice-wheat or bajrawheat systems. These crops have low photosynthetic efficiency and yield potential, as reflected in lower values of SIF throughout the agricultural years. The average NPP for Hissar was just above 8 tonnes/ha in these three years. Preliminary analysis revealed that SIF from GOME-2 could capture variation in photosynthetic productivity due to diversity in cropping systems practised over the IGP.

Thus the present study shows that SIF at enhanced space-time resolution in future would offer possibility of improving forecasts of agricultural productivity and minimizing uncertainty in carbon accounting. Results in general point to the significance of SIF in the precise mapping of the spatio-temporal changes in crop productivity. However, the variability in the predictive power of
SIF across different years warrants a more detailed study by integrating existing time-series remotely sensed vegetation indices, meteorological parameters and groundbased data for robust modelling. Though the current coarse resolution of SIF data restricts their application to regional scales, the future satellite data (NASA's orbiting carbon observatory-2) will provide impetus to satellitebased mapping of SIF at unprecedently finer scales.

1. Smorenburg, K. et al., Remote sensing of solar induced fluorescence of vegetation. SPIE Proc.: Remote Sensing Agric., Ecosyst. Hydrol. III, 2000, p. 4542.

2. Meroni, M., Rossini, M., Guanter, L., Alonso, L., Rascher, U., Colombo, R. and Moreno, J., Remote sensing of solar-induced chlorophyll fluorescence: review of methods and applications. Remote Sensing Environ., 2009, 113, 2037-2051.

3. Porcar-Castell, A. et al., Linking chlorophyll $a$ fluorescence to photosynthesis for remote sensing applications: mechanisms and challenges. J. Exp. Bot., 2014, 65, 4065-4095.

4. Frankenberg, C. et al., New global observations of the terrestrial carbon cycle from GOSAT: patterns of plant fluorescence with gross primary productivity. Geophys. Res. Lett., 2011, 38, L03801; doi:10.1029/2010GL045896.

5. Guanter, L. et al., Retrieval and global assessment of terrestrial chlorophyll fluorescence from GOSAT space measurements. Remote Sensing Environ., 2012, 121, 236-251.

6. Joiner, J., Yoshida, Y., Vasilkov, A. P., Yoshida, Y., Corp, L. A. and Middleton, E. M., First observations of global and seasonal terrestrial chlorophyll fluorescence from space. Biogeosciences, $2011,8,637-651$

7. Joiner, J. et al., Global monitoring of terrestrial chlorophyll fluorescence from moderate-spectral-resolution near-infrared satellite measurements: methodology, simulations, and application to GOME-2. Atmos. Meas. Tech., 2013, 6, 2803-2823.

8. Guanter, L. et al., Global and time-resolved monitoring of crop photosynthesis with chlorophyll fluorescence. Proc. Natl. Acad. Sci. USA, 2014, 111(14), E1327-E1333.

9. Pal, D. K., Bhattacharyya, T., Srivastava, P., Chandran, P. and Ray, S. K., Soils of the Indo-Gangetic Plains: their historical perspective and management. Curr. Sci., 2009, 96(9), 1193-1202.

10. Nayak, R. K., Patel, N. R. and Dadhwal, V. K., Estimation and analysis of terrestrial net primary productivity over India by remote-sensing-driven terrestrial biosphere model. Environ. Monit. Assess., 2010, 1, 195-213.

ACKNOWLEDGEMENTS. This study was jointly carried out between the Indian Institute of Remote Sensing, Dehradun and University of Technology Sydney, Australia under the Australia and India Council project.

Received 19 July 2016; revised accepted 9 November 2017

doi: $10.18520 / \mathrm{cs} / \mathrm{v} 114 / \mathrm{i} 06 / 1333-1337$ 
Copyright of Current Science (00113891) is the property of Indian Academy of Sciences and its content may not be copied or emailed to multiple sites or posted to a listserv without the copyright holder's express written permission. However, users may print, download, or email articles for individual use. 